Časopis za unapređenje stočarstva

Journal for the

stockbreeding advancement

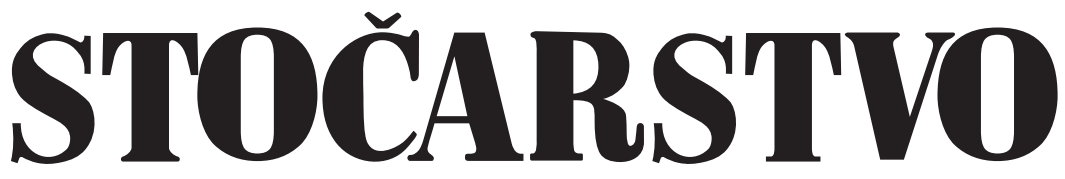

Knjiga

Volume

73/2019

Siječanj - Prosinac

Svezak

January - December

Number

1-2

Reprodukcija, uzgoj i korištenje gospodarskih vrsta domaćih životinja

\author{
Reproduction, \\ breeding and use of \\ economic breeds of farm animals
}


Radovi objavljeni u časopisu "Stočarstvo" redovito se referiraju u uglednim svjetskim bazama podataka i referalnim časopisima - Papers published in "Stočarstvo" are regularly referred to in the renowned world data beses and reference Journals: CAB Abstracts, AGRICOLA, AGRIS, FSTA, World Translations Index, Animal Breeding Abstracts, Dairy Science Abstracts, Index of Current Research on Pigs, Pig News and Informations, Chemical Abstracts. 


\title{
UTJECAJ GENOTIPA NA SVOJSTVA POLOVICA I KVALITETU MESA TOVLJENIKA CRNIH SLAVONSKIH SVINJA I NJIHOVIH KRIŽANACA S DUROKOM UZGAJANIH U EKSTENZIVNOM SUSTAVU
}

\author{
Kristina Gvozdanović, J. Kundid, V. Margeta, Dalida Galović, \\ Polonca Margeta, Ž. Radišić
}

\begin{abstract}
Sažetak
Cilj istraživanja bio je utvrditi utjecaj genotipa na svojstva polovica i kvalitetu mesa tovljenika crnih slavonskih svinja (CS) te križanaca crnih slavonskih svinja s durokom (CSxD) uzgajanih u ekstenzivnom sustavu. U istraživanju je korišteno 40 svinja koje su podijeljene u dvije skupine s obzirom na genotip; crne slavonske svinje (CS, $n=20)$ te križanci crne slavonske svinje s durokom $(C S x D, n=20)$. Svinje su zaklane u dobi od 550 dana. Od klaoničkih svojstava i parametara kvalitete polovice u radu su prikazani rezultati mase polovica, dužine polovica (mjera „a“ i mjera „b“), debljine slanine (s) i mišića

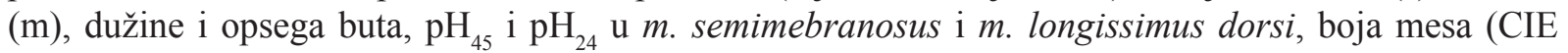
L*a*b*), kalo kuhanja i instrumentalna nježnost mesa. Rezultati istraživanja su ukazali na to da se križanjem crne slavonske pasmine i durok pasmine mogu proizvesti križanci dužeg trupa te većeg opsega buta u odnosu na čiste crne slavonske svinje. Nadalje, kod crnih slavonskih svinja je utvrđena veća debljina leđne slanine u odnosu na križance s durokom. Statistički značajan utjecaj genotipa utvrđen je za $\mathrm{pH}_{24}$ izmjerenu u butu $(\mathrm{P}<0,001), \mathrm{CIE} \mathrm{a}^{*}$ vrijednost boje $(\mathrm{P}<0,01)$, kalo kuhanja $(\mathrm{P}<0,001)$ te instrumentalnu nježnost mesa $(\mathrm{P}<0,01)$.
\end{abstract}

Ključne riječi: svinje, kvaliteta mesa, genotip, crna slavonska svinja, durok

\section{Uvod}

Crna slavonska svinja je autohtona pasmina svinja u Republici Hrvatskoj koja se tradicionalno uzgaja u ekstenzivnom sustavu. Ovaj način uzgoja crnih slavonskih svinja podrazumijeva držanje na pašnjacima tijekom proljeća, ljeta i rane jeseni dok su svinje tijekom zimskog razdoblja boravile u zatvorenim objektima (Margeta i sur., 2018.a). Ekstenzivni sustav osim što ne zahtjeva visoka ulaganja u izgradnju objekata, također osigurava svinjama prirodno okruženje koje je u skladu s kriterijima dobrobiti (Margeta, 2016.). Crna slavonska svinja je u prošlosti bila najraširenija pasmina svinja na području Slavonije, te se uglavnom koristila za proizvodnju masti i tradicionalnih prehrambenih proizvoda Ona pripada skupini svinja masno-mesnog tipa te se odlikuje mesom izvrsne kvalitete pogodne za proizvodnju visoko vrijednih proizvoda (šunka, kulen) (Karolyi i sur., 2010.). Obzirom na to da je udio masnog tkiva u trupu crnih slavonskih svinja veći u odnosu na udio mišićnog tkiva, iskoristivost osnovnih dijelova (but, lopatica) bit će manja u odnosu na plemenite pasmine svinja. Crna slavonska pasmina svinja ima slabija proizvodna svojstva koja je moguće poboljšati križanjem s nekom od plemenitih pasmina. Upravo križanjem s durok pasminom svinja se može postići poboljšanje proizvodnih svojstava bez negativnog utjecaja na kvalitetu mesa (Pugliese i sur., 2012.). Razlog tomu je viši sadržaj unutarmišićne (intramuskularne) masti u odnosu

dr.sc. Kristina Gvozdanović, e-mail: kgvozdanovic@fazos.hr, Josip Kundid, mag.ing.agr., doc.dr.sc. Vladimir Margeta, izv.prof.sc. Dalida Galović, dr.sc. Polonca Margeta, Žarko Radišić, dipl.ing. - Sveučilište Josipa Jurja Strossmayera u Osijeku, Fakultet agrobiotehničkih znanosti Osijek, Vladimira Preloga 1, 31000 Osijek 
na potkožnu masnoću u usporedbi s drugim plemenitim pasminama svinja (Wood i sur., 2008.). Uočeno je da se kod crnih slavonskih svinja postotak intramuskularne masti kreće od oko 5,0\% do 7,2\% (Margeta i sur., 2018.) dok je kod durok pasmine sadržaj intramuskularne masti od 2,40\% do 2,79\% (Yung i sur., 2015.). Sadržaj intramuskularne masti utječe na okus i mekoću mesa, no također i na preradbenu vrijednost mesa (Karolyi, 2007.). Jedan od glavnih razloga križanja autohtonih pasmina svinja s nekom od plemenitih pasmina je proizvodnja križanaca koji će rasti brže te ostvarivati veće dnevne priraste, imati veće osnovne dijelove, prvenstveno but, a ujedno će imati i poboljšana proizvodna svojstva. Ranijim istraživanjem potvrđeno je da križanci nastali sparivanjem crnih slavonskih svinja s durokom ostvaruju veće priraste te tjelesne težine tijekom različitih faza uzgoja (Kušec i sur., 2019.). Izquierdo i sur. (2018.) navode da križanjem različitih genotipova iberijske pasmine svinja s durokom dolazi do poboljšanja kvalitete polovica i mesa F1 križanaca.

Cilj istraživanja bio je istražiti utjecaj genotipa, odnosno križanja crnih slavonskih svinja s durok pasminom na najvažnije parametre kvalitete polovica i mesa crnih slavonskih svinja i njihovih križanca sa svinjama pasmine durok.

\section{Materijal i metode}

\section{Životinje}

Istraživanje je provedeno na 40 svinja od kojih je bilo 20 svinja crne slavonske pasmine (CS) te 20 križanaca crne slavonske svinje i duroka (CSxD). Obje skupine svinja su tijekom istog vremenskog perioda uzgajane u ekstenzivnim uvjetima gdje je osnovu hranidbe tijekom ljetnog razdoblja činila smjesa 50\% kukuruza, 30\% ječma, 10\% zobi, 10\% soje i zelene lucerne dok se hranidba svinja tijekom zime zasnivala na sjenu lucerne uz dodatak smjese žitarica. Nakon završetka tovnog razdoblja, svinje su zaklane u komercijalnoj klaonici pri dobi od 550 dana i prosječnim težinama od 135 do $150 \mathrm{~kg}$.

\section{Analiza svojstava polovice i kvalitete mesa}

$\mathrm{Na}$ liniji klanja uzete su sljedeće mjere polovica: masa polovica, dužina polovica (mjera ,a“ i mjera „,b"), debljina slanine (s) i mišića (m) te dužina i opseg buta. Mjera ,aa određena je od prvog rebra do os pubis, dok je mjera „b“ uzeta od atlasa do os pubis. Debljina leđne slanine (s) određena je na mjestu u kojem $m$. gluteus medius najdublje prodire u slaninu. Najkraća udaljenosti kranijalnog završetka $m$. gluteus medius i dorzalnog spinalnog kanala označavala je mjesto određivanja debljine mišića (m). Opseg buta izmjeren je na najširem dijelu buta dok je njegova duljina izmjerena od prednjeg dijela symphysis pubis do skočnog zgloba. Određeni su sljedeći parametri kvalitete mesa: $\mathrm{pH}_{45}$ i $\mathrm{pH}_{24} \mathrm{u}$ m. semimebranosus i $m$. longissimus dorsi, boja mesa (CIE L*, a*, b*), kalo kuhanja i instrumentalna nježnost mesa. Vrijednosti $\mathrm{pH}_{45}$ su određene 45 minuta post mortem ubodom MP120-B pH metrom (Mettler Tolledo, AG) u odsječak $m$. longissimus dorsi te $m$. semimebranosus. Vrijednosti $\mathrm{pH}_{24}$ određene su nakon 24 sata hlađenja

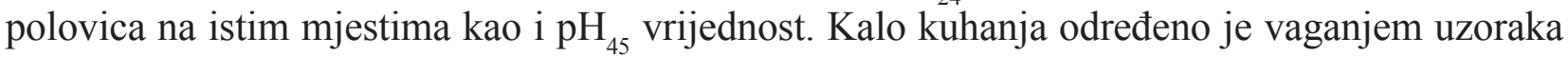
prije i nakon kuhanja uzoraka u vodenoj kupelji na $73^{\circ} \mathrm{C}$. Boja mesa je određena Minolta kolorimetrom (CR 300, Minolta Camera Co. Ltd., Osaka Japan) na odsječku m. longissimus dorsi 45 minuta post mortem. Standard pri mjerenju boje bila je bijela pločica ( $L^{*}=93,30 ; a^{*}=0,32$; $\left.\mathrm{b}^{*}=0,33\right)$. Tekstura mesa određena je pomoću Warner-Bratzler na TA.XTplus Texture Analyser-u (Stable Micro Systems, London, UK) na uzorcima $m$. longissimus dorsi debljine $3 \mathrm{~cm}$. 


\section{Statistička obrada podataka}

Statistička obrada podataka provedena je koristeći SAS V9.4 paket (SAS, 2013) uz primjenu procedure GLM. Za analizu je korišten statistički model:

$$
\mathrm{y}_{\mathrm{ij}}=\mu+\mathrm{b}\left(\mathrm{x}_{\mathrm{ij}}-\overline{\mathbf{x}}\right)+\mathrm{Gj}+\mathrm{e}_{\mathrm{ij}}
$$

gdje je $y_{i j}$ vrijednost opažanja, $\mu$ srednja vrijednost, $b\left(x_{i j}-\overline{\mathbf{x}}\right)$ utjecaj tjelesne mase izražen kao kovarijabla, $G_{j}$ sistematski utjecaj genotipa i $e_{i j}$ slučajna greška.

\section{Rezultati i rasprava}

Tablica 1. Statistički pokazatelji kvalitete polovica

Table 1 Statistical indicators of meat quality

\begin{tabular}{lccccc}
\hline \multirow{2}{*}{ Pokazatelji } & \multicolumn{2}{c}{ CSxD } & \multicolumn{2}{c}{ CS } & p-value \\
\cline { 2 - 5 } & $\overline{\mathbf{x}}$ & $\mathrm{SE}$ & $\overline{\mathbf{x}}$ & $\mathrm{SE}$ & \\
\hline $\begin{array}{l}\text { Masa trupa, } \mathrm{kg} \\
\text { Carcass weight, } \mathrm{kg}\end{array}$ & 102,616 & 5,071 & 98,605 & 4,447 & 0,591 \\
\hline $\begin{array}{l}\text { Debljina slanine, } \mathrm{mm} \\
\text { Fat thickness, mm }\end{array}$ & 35,234 & 1,905 & 39,187 & 1,761 & 0,139 \\
\hline $\begin{array}{l}\text { Debljina mišića, mm } \\
\text { Muscle thickness, mm }\end{array}$ & 63,192 & 1,386 & 60,850 & 1,281 & 0,063 \\
\hline „a“, cm & 91,920 & 1,620 & 89,384 & 1,498 & 0,262 \\
\hline „b“, cm & 108,022 & 1,358 & 107,754 & 1,256 & 0,886 \\
\hline $\begin{array}{l}\text { Dužina } \\
\text { Ham }_{\mathrm{L}}, \mathrm{cm}\end{array}$ & 35,248 & 0,589 & 36,523 & 0,544 & 0,124 \\
\hline $\begin{array}{l}\text { Opseg }_{\mathrm{B}}, \mathrm{cm} \\
\text { Ham }_{\mathrm{C}}, \mathrm{cm}\end{array}$ & 71,244 & 0,914 & 70,802 & 0,845 & 0,727 \\
\hline
\end{tabular}

CSxD- križanci crna slavonska pasmina $\mathrm{x}$ durok pasmina; CS- crna slavonska pasmina $* \mathrm{P}<0,05 ; * * \mathrm{P}<0,01 ; * * * \mathrm{P}<0,001$.

Tablicom 1 su prosječne vrijednosti kvalitete polovica dobivene metodom najmanjih kvadrata. Križanci CSxD ostvarili su veću masu trupa te dužinu trupa izmjerenu mjerom „a“ i mjerom „,b“ u odnosu na CS svinje. Istraživanjem Kušeca i sur. (2019.) uočeno je da su križanci crne slavonske svinje s durokom imali veću završne težine u odnosu na čiste crne slavonske svinje. Nadalje, autori su zaključili da križanci ostvaruju brži porast tijekom cijelog uzgojnog razdoblja. Luković i sur. (2007.) navode da su križanci s durokom imali veće duljine polovica $(101,4 \mathrm{~cm})$ od CS svinja $(96,2 \mathrm{~cm})$. Põldvere i sur. (2015.) su utvrdili da se križanjem durok pasmine s autohtonim pasminama svinja značajno utječe na svojstva polovica svinja, odnosno na njihovu duljinu. Omjer debljine mišića i debljine slanine predstavlja jedno od važnijih svojstava u uzgoju svinja. Poznato je da se križanjem autohtonih pasmina svinja s durokom smanjuje debljina slanine te povećava debljina mišićnog tkiva (Robina i sur., 2013.). Tako je u našem istraživanju veća debljina slanine te man- 
ja debljina mišića utvrđena je kod CS svinja, dok su križanci imali veću debljinu mišića i tanju slaninu. Prema rezultatima Gvozdanović i sur. (2018.) crne slavonske svinje prosječno iste težine imale su debljinu leđne slanine $(21,66 \mathrm{~cm})$ te debljinu mišića $(57,70 \mathrm{~cm})$ što je sukladno našim rezultatima. Szulc i sur. (2012.) su istražili utjecaj križanja duroka s poljskom autohtonom pasminom svinja Złotnicka Spotted na svojstva polovica i kvalitetu mesa. Rezultati njihova istraživanja su pokazali da križanci s durokom imaju značajnu manju debljinu leđne slanine od svinja Złotnicka Spotted pasmine. Nadalje, brojnim istraživanjima je utvrđen utjecaj sustava držanja na debljinu leđne slanine i mišića kod autohtonih pasmina svinja (Tomažin i sur., 2019.; Djurkin Kušec i sur., 2017.; Dostálová i sur., 2012.; Petrović i sur., 2012.). Tako je primjerice utvrđeno da crne slavonske svinje uzgajane u ekstenzivnom sustavu ostvaruju značajno veće vrijednosti debljine mišića $(71,53 \mathrm{~mm})$ i manje vrijednosti debljine leđne slanine $(37,75 \mathrm{~mm}) \mathrm{u}$ odnosu na uzgoj svinja na dubokoj stelji (Djurkin Kušec i sur., 2017.). Dužina buta bila je veća kod CS dok je veći opseg buta utvrđen kod križanaca CSxD. Nije utvrđen statistički značajan utjecaj genotipa na $\mathrm{pH}_{45} \mathrm{SM}, \mathrm{pH}_{45} \mathrm{LM}, \mathrm{pH}_{24} \mathrm{LD}$, CIE L* i CIE b $(\mathrm{P}>0,05)$.

Tablica 2. Statistički pokazatelji kvalitete mesa

Table 2 Statistical indicators of carcass traits

\begin{tabular}{|c|c|c|c|c|c|}
\hline \multirow{2}{*}{ Pokazatelji } & \multicolumn{2}{|c|}{ CSxD } & \multicolumn{2}{|c|}{$\mathrm{CS}$} & \multirow{2}{*}{$\mathrm{P}$} \\
\hline & $\overline{\mathbf{x}}$ & SE & $\overline{\mathbf{x}}$ & SE & \\
\hline $\mathrm{pH}_{45} \mathrm{SM}$ & 6,483 & 0,037 & 6,503 & 0,036 & 0,7046 \\
\hline $\mathrm{pH}_{45} \mathrm{LM}$ & 6,414 & 0,033 & 6,404 & 0,031 & 0,8478 \\
\hline $\mathrm{pH}_{24} \mathrm{SM}$ & 5,597 & 0,023 & 5,689 & 0,021 & $0,0071 * * *$ \\
\hline $\mathrm{pH}_{24} \mathrm{LD}$ & 5,659 & 0,027 & 5,629 & 0,025 & 0,428 \\
\hline CIE L* & 51,135 & 0,844 & 50,306 & 0,800 & 0,484 \\
\hline CIE a* & 10,962 & 0,340 & 9,575 & 0,322 & $0,005^{* *}$ \\
\hline CIE $b^{*}$ & 4,173 & 0,212 & 3,681 & 0,201 & 0,104 \\
\hline $\begin{array}{l}\text { Kalo kuhanja, \% } \\
\text { Cooking loss, \% }\end{array}$ & 36,995 & 0,703 & 31,499 & 0,666 & $0,0001 * * *$ \\
\hline WBSF, n & 42,193 & 1,942 & 50,345 & 1,841 & $0,0047 * *$ \\
\hline
\end{tabular}

CSxD- križanci crna slavonska pasmina x durok pasmina; CS- crna slavonska pasmina

SM- m. semimembranosus; LM- m.longissimus dorsi

$* \mathrm{P}<0,05 ; * * \mathrm{P}<0,01 ; * * * \mathrm{P}<0,001$.

Statistički pokazatelji kvalitete mesa su prikazani Tablicom 2. Iako nije uočena statistički značajna razlika između CS i CSxD svinja u pogledu početne $\mathrm{pH}$ vrijednosti, utvrđeno je da su početna i završna $\mathrm{pH}$ vrijednost izmjerene u SM bile je veće kod CS svinja, dok su navedeni parametri izmjereni u LD bili viši kod CSxD svinja. Statistički značajna razlika utvrđena je samo za završnu pH vrijednosti izmjerenu u SM $(\mathrm{P}<0,001)$. Više $\mathrm{pH}$ vrijednosti kod CSxD mogu biti posljedica sporije post mortem glikolize kod durok pasmine što može dovesti do 
pojave tvrdog, suhog i čvrstog mesa (Lattore i sur., 2003.). Rezultati istraživanja bili su sukladni rezultatima Baković i sur. (2016.) koji navode da se početne pH vrijednosti CS svinja uzgajanih u ekstenzivnom sustavu kreću od 6,51 do 6,40 mjerenih u LD i SM mišiću dok su završne $\mathrm{pH}$ vrijednosti 5,96 u SM te 5,78 u LD. Prema rezultatima Djurkin Kušec i sur. (2017.) početna $\mathrm{pH}$ vrijednost kretala se od 6,44 u SM te 6,48 u LD dok je završna $\mathrm{pH}$ vrijednost bila $5,69 \mathrm{u} \mathrm{LD}$ te 5,64 u SM. Luković i sur. (2007) su dobili početne $\mathrm{pH}$ vrijednosti izmjerene u LD 6,23 te u SM 6,35 kod CS svinja, dok su kod CSxD križanaca one iznosile 6,11 i 6,19. Vrijednosti završne $\mathrm{pH}$ vrijednosti bile su 5,28 kod CS svinja te 5,42 kod CSxD. CIE L* vrijednosti boje bila je veća kod CSxD u odnosu na CS. Dobivene vrijednosti boje L* bile su niže od 53 ( CIE L*>53) što je u skladu s preporukama za boju mesa (Honikel, 1999.). Dobiveni rezultati su sukladni rezultatima Lukovića i sur. (2007.) koji su također dobili više CIE L* vrijednosti kod svinja križanih s durokom (CIE L* 54,00) u odnosu na čiste crne slavonske svinje (CIE L* 51,52). Nadalje, CIE a* te CIE b* vrijednosti boje su bile već kod CSxD križanaca u odnosu na CS svinje. Kod autohtonih pasmina svinja je utvrđen veći udio oksidativnih vlakana što dovodi do većeg udjela mioglobina. Upravo je to razlog tamnijeg mesa autohtonih pasmina svinja u odnosu na plemenite pasmine (Wojtysiak i Połtowicz, 2014.). Nadalje, autohtone pasmine svinja se tradicionalno uzgajaju tijekom dužeg vremenskog perioda ekstenzivnim sustavom što utječe na boju mesa. Naime, s povećanjem dobi svinja dolazi do povećavanja koncentracije mioglobina (Mayoral i sur., 1999.). Kalo kuhanja bilo je veće kod križanaca CSxD u odnosu na čiste crne slavonske svinje. Prema Djurkin Kušec i sur. (2017.) kalo kuhanja kod crnih svinja uzgajanih u ekstenzivnom sustavu iznosio je 33,84 dok su Baković i sur. (2016.) dobili vrijednost od 32,38 što je više nego vrijednost dobivena u našem istraživanju $(31,449)$. U odnosu na druge europske autohtone pasmine svinja, primjerice Cinta Senese (Pugliese i sur., 2005.) ili Celta pasminu svinja (Franco i sur., 2016.) crna slavonska svinja ima višu vrijednost kala kuhanja, dok u odnosu na mangulicu ima manju vrijednost kala kuhanja (Stanišić i sur., 2013.). Križanci CSxD imali su statistički značajno manju instrumentalnu vrijednost mesa u odnosu na crne slavonske svinje. Dobiveni rezultati imaju manju vrijednosti od prethodno objavljenih rezultata Baković i sur. (2016.) i Djurkin Kušec i sur (2017.). Statistički značajan utjecaj genotipa na parametre kvalitete mesa uočen je kod završne $\mathrm{pH}$ vrijednosti izmjerene u SM $(\mathrm{P}<0,001)$, CIE a* vrijednosti boje mesa $(\mathrm{P}<0,01)$, kala kuhanja $(\mathrm{P}<0,001)$ te instrumentalne nježnosti mesa $(\mathrm{P}<0,01)$.

\section{Zaključak}

Sustavnim sparivanjem autohtonih pasmina svinja s nekom od plemenitih pasmina može doći do poboljšavanja proizvodnih svojstava križanaca no i narušavanja njihove kvalitete mesa. Uzimajući u obzir da se crna slavonska svinja odlikuje izvrsnom kvalitetom mesa koje je pogodno za preradu u tradicionalne proizvode, treba voditi računa o odabiru pasmine koja će se koristiti u postupcima križanja. Križanje durok pasmine svinja s crnom slavonskom pasminom ima pozitivan utjecaj na rast svinja i svojstva polovica bez negativnog utjecaja na kvalitetu mesa koje je jedna od najvažnijih karakteristika crnih slavonskih svinja.

\section{Napomena}

Istraživanja neophodna za ovaj rad dio su VIP projekta 2015-13/05 kojeg financira Ministarstvo poljoprivrede RH „Razvoj poljoprivrednih sustava i standardizacija kvalitete mesa crne slavonske svinje“. 


\section{LITERATURA}

1. Baković, M., Gvozdanović, K., Galović, D., Radišić, Ž., Margeta, V. (2016.): Klaonička svojstva tovljenika crne slavonske svinje iz ekstenzivnog sustava držanja, Krmiva: časopis o hranidbi životinja, proizvodnji i tehnologiji krme, 58(1):3-8.

2. Djurkin Kušec, I., Buha, I., Margeta, V., Gvozdanović, K., Radišić, Ž., Komlenić, M., Kušec, G. (2017.): Carcass Composition and Meat Quality of Crna Slavonska Pigs from Two Different Housing Conditions. Agriculturae Conspectus Scientificus, 82(3): 221-225.

3. Dostálová, A., Koucký, M., Vališ, L., Šimečková, M. (2012.): Evaluation of fattening performance, carcass traits and meat characteristics of Prestice Black-Pied pigs in the organic free-range and conventional system. Research in pig breeding, 6: 15-19.

4. Franco, D., Carballo, J., Bermñudez, R., Lorenzo, J. M. (2016.): Effect of genotype and slaughter age on carcass traits and meat quality of the Celta pig breed in extensive system. Annals of Animal Science, 16(1): 259-273.

5. Gvozdanovic, K., Margeta, V., Kušec, I. D., Margeta, P., Radišić, Ž., Kušec, G. (2018.): Comparison of carcass and meat quality traits of Black Slavonian pigs regarding the duration of fattening period. Archivos de zootecnia, (1): 205-208.

6. Honikel, K.O. (1998.): Reference methods for the assessment of physical characteristics of meat. Meat Science, 49:447-457.

7. Izquierdo, M., García, F. I. H., Parra, M. L., del Rosario González, A. I., Montero, A., Pérez, M. A., Garrido, N. (2018.): Carcass and meat traits of different Iberian pig genotypes fed in a traditional extensive system. Archivos de zootecnia, (1): 201-204.

8. Jung, J. H., Shim, K. S., Na, C. S., Choe, H. S. (2015.): Studies on intramuscular fat percentage in live swine using real-time ultrasound to determine pork quality. Asian-Australasian journal of animal sciences, 28(3): 318.

9. Karolyi, D., Salajpal, K., Luković, Z. (2010.): Crna slavonska svinja. Meso: prvi hrvatski časopis o mesu, 12(4): 222-230.

10. Karolyi, D., Salajpal, K., Kiš, G., Đikić, M., Jurić, I. (2007.): Influence of finishing diet on fatty acid profile of longissimus muscle of Black Slavonian pigs. Poljoprivreda, 13(1): 176-179.

11. Kušec, G., Gvozdanović, K., Djurkin Kušec, I., Margeta, V., Galović, D., Radišić, Ž. (2019.): Changes in carcass composition of Black Slavonian pigs and their crossbreds with Duroc during growth. Journal of Central European Agriculture, 20(1): 43-49.

12. Latorre, M.A., Medel, P., Fuentetaja, A., Lázaro, R., Mateos,. GG. (2003.): Effect of gender, terminal sire line and age at slaughter on performance, carcass characteristics and meat quality of heavy pigs. Animal science, 77(1): 33-45.

13. Luković, Z., Uremović, M., Konjačić, M., Uremović, Z., Vnučec, I., Prpić, Z., Kos, I. (2007.): Proizvodna svojstva tovljenika crne slavonske pasmine i križanaca s durokom. In 42 hrvatski \& 2 međunarodni Simpozij agronoma, Opatija. Hrvatska. pp. 220-221.

14. Margeta, V., Gvozdanović, K., Kušec, G., Djurkin Kušec, I. Batorek-Lukač, N. (2018). Black Slavonian (Crna slavonska) pig. A study of project TREASURE. In Čandek-Potokar M, Nieto R (Eds.) European Local Pig Breeds - Diversity and Performance. pp. 87-101, Intech Open, London. 
15. Margeta, V., Gvozdanović, K., Margeta, P., Kušec, I. D., Radišić, Ž., Galović, D., Kušec, G. (2016.): Low input production system suitable for Black Slavonian pig breeding. Acta argiculturae Slovenica, 5: 122-125.

16. Mayoral, A. I., Dorado, M., Guillén, M. T., Robina, A., Vivo, J. M., Vazquez, C. (1999.): Development of meat and carcass quality characteristics in Iberian pigs reared out-doors. Meat Science, 52: 315-324.

17. Petrović, M., Radović, Č., Parunović, N., Radojković, D., Savić, R. (2012.): Composition of carcass sides and quality of meat from swallow-belly Mangalitsa reared in two systems. Biotechnology in Animal Husbandry, 28(2): 303-311.

18. Põldvere, A., Tanavots, A., Saar, R., Torga, T., Kaart, T., Soidla, R., Mahla, T., Andreson, H., Lepsalu, L. (2015.): Effect of imported Duroc boars on meat quality of finishing pigs in Estonia. Agronomy Research, 13(4): 1040-1052.

19. Pugliese, C., Bozzi, R., Campodoni, G., Acciaioli, A., Franci, O., Gandini, G. (2005.): Performance of Cinta Senese pigs reared outdoors and indoors.: 1. Meat and subcutaneous fat characteristics. Meat Science, 69(3): 459-464.

20. Pugliese, C., Sirtori, F. (2012.): Quality of meat and meat products produced from southern European pig breeds. Meat science, 90(3): 511-518.

21. Robina, A., Viguera, J., Perez-Palacios, T., Mayoral, A. I., Vivo, J. M., Guillen, M. T., Ruiz, J. (2013.): Carcass and meat quality traits of Iberian pig as affected by sex and crossbreeding with different Duroc genetic lines. Spanish Journal of Agricultural Research, 11(4): 1057-1067.

22. SAS Institute Inc. (2013) SAS Version 9.4. Cary, NC, USA: SAS Institute Inc.

23. Stanišić, N., Petrović, M., Radović, Č., Gogić, M., Parunović, N., Stajić, S., Petričević, M. (2013.): The effect of gender and breed on some properties of pig meat. Biotechnology in Animal Husbandry, 29(4): 651-658.

24. Szulc, K., Skrzypczak, E., Buczyński, J. T., Stanisławski, D., Jankowska-Mąkosa, A., Knecht, D. (2012.): Evaluation of fattening and slaughter performance and determination of meat quality in Złotnicka Spotted pigs and their crosses with the Duroc breed. Czech Journal of Animal Science, 57(3): 95-107.

25. Tomažin, U., Batorek-Lukač, N., Škrlep, M., Prevolnik-Povše, M., Čandek-Potokar, M. (2019.): Meat and fat quality of Krškopolje pigs reared in conventional and organic production systems. Animal, 13(5): 1103-1110.

26. Wood, J. D., M. Enser, A. V. Fisher, G. R. Nute, P. R. Sheard, R. I. Richardson, S. I. Hughes, F. M. Whittington (2008.): Fat deposition, fatty acid composition and meat quality: A review. Meat science 78(4): 343-358.

27. Wojtysiak, D., Połtowicz, K. (2014.): Carcass quality, physico-chemical parameters, muscle fibre traits and myosin heavy chain composition of $m$. longissimus lumborum from Puławska and Polish Large White pigs. Meat science, 97(4): 395-403. 


\title{
INFLUENCE OF GENOTYPE ON CARCASS AND MEAT QUALITY OF CRNA SLAVONSKA PIG BREED AND THEIR CROSSBRED WITH DUROC REARED UNDER EXTENSIVE PRODUCTION SYSTEM
}

\begin{abstract}
Summary
The aim of the study was to investigate influence of genotype on carcass composition and meat quality of Black Slavonian fattening pigs reared in extensive keeping conditions. Present study was conducted on 40 pigs divided into two groups regarding the genotype; Black Slavonian $(C S, n=20)$ and crossbreds of Black Slavonian and Duroc (CSxD, $n=20)$. Pigs were slaughtered at the age of 550. Carcass and meat quality traits were collected: carcass weight, carcass length) measure „a“ and „b"), muscle (m) and backfat (s) thickness, as well as ham length and circumference, $\mathrm{pH}_{45}$ and $\mathrm{pH}_{24}$ in m.semimembranosus and m.longissimus dorsi, meat color (CIE L*a* $\mathrm{b}^{*}$ ), cooking loss and WB shear force. The results showed that crossing the Black Slavonian pigs with Duroc resulted in production of crosses with longer carcass and ham circumference. Moreover, pure Black Slavonian pigs had higher backfat thickness and lover muscle thickness than crossbred pigs. Genotype had no significant influence on carcass traits from both groups of pigs. Statistically significant influence of genotype was reported for $\mathrm{pH}_{24}(\mathrm{P}<0.001)$ measured in $m$. semimembranosus, $\mathrm{CIE}$ a* meat color $(\mathrm{P}<0.01)$, cooking loss $(\mathrm{P}<0.001)$ and instrumental tenderness $(\mathrm{P}<0.01)$.
\end{abstract}

Key words: pigs, meat quality, rearing system, Black Slavonian pig breed, Duroc

Primljeno: 03.09.2019.

Prihvaćeno: 19.09.2019. 